\title{
Social connections among parents of pre-school-age children in an inner and outer area of Melbourne, Australia
}

\section{Fiona Andrews}

School of Health and Social Development

Centre for Health through Action on Social Exclusion (CHASE), Faculty of Health

Deakin University

\section{Julia Shelley}

School of Health and Social Development

Centre for Health through Action on Social Exclusion (CHASE), Faculty of Health

Deakin University

\section{Stephanie Rich}

School of Health and Social Development

Deakin University

\author{
Alexandra James \\ School of Health and Social Development \\ Deakin University
}

\section{Abstract}

Parents' social connectedness is an important factor in child health and development 
outcomes and has been strongly linked to place. This study aimed to compare social connectedness amongst parents in inner versus outer-suburbs of Melbourne using a mixed methods approach. Parents were recruited via playgroups, mother's groups and preschools and interviewed face- to-face regarding their social networks, with a second open-ended interview focusing on parents' ideals and experiences of raising children in their current location. Parents in the two areas identified a similar number of contacts, but had differently structured networks. Outer-suburban parents were more likely than inner-suburban parents to have very few contacts, and to name their general practitioner as among their significant contacts. They were less likely to have more extended networks or to include neighbours among their contacts. Parents in both areas had met at least some of their network members through local organisations or services with outer-suburban parents having met a greater proportion of their contacts in this way. Qualitative interview data supported the network analysis revealing the different priorities parents placed on neighbours, barriers experienced in connecting with neighbours in the outer- suburbs and the consequent heavy reliance on organised activities to form social connections. The different types of social connections parents in inner and outer Melbourne made in relation to raising their preschool-aged children revealed in this study have implications for both service delivery and social planning of new developments.

Keywords: Social networks, social connectedness, suburbs, neighbourhood, preschool-age children, parents

\section{Introduction}

Social connections are known to be important for good physical and mental health across the lifespan (Berkman, 1995; Holt-Lunstad, Smith, \& Layton, 2010; Morgan \& Eastwood, 2014; Small, Taft, \& Brown, 2011). This is particularly the case during the early years of parenting as this is a life stage where many parents report an increased need for informal support (Devolin et al., 2012; Hanna, Edgecombe, Jackson, \& Newman, 2002; Hogg \& Worth, 2009; Miller \& Darlington, 2002). At the same time 
however, women in particular, can suffer from loneliness as existing social networks are lost as a result of moving to more 'family friendly' suburbs and/or changing priorities with regard to immediate support needs (Baker, 2012; Bost, Cox, Burchinal, \& Payne, 2002). This study thus focuses on social connectedness amongst parents of preschoolage children.

In addition to being important for parents, in recent years increasing evidence has demonstrated that the extent and types of social connectedness of parents has an impact on a range of outcomes for children and adolescents, including health, educational attainment, intellectual and social development, risk-taking behaviours and general wellbeing (Cattrel, 2011; Caughy, O'Campo, \& Muntaner, 2003; Edwards, 2006; Edwards \& Bromfield, 2009, 2010; Xue, Leventhal, Brooks-Gunn, \& Felton, 2005). A detailed systematic review by McPherson et al. (2013) concluded that children and adolescents with access to a high quantity and quality of social support networks, including through their parents' social networks, had better outcomes in many domains. These included general health, quality of life and/or wellbeing, were more likely to report higher self-worth/esteem, or had fewer negative outcomes.

Two pathways have been proposed as important in these relationships. The first postulates parents' networks have direct influences on children (for example, by the number or quality of relationships children are directly exposed to), while the second postulates indirect impacts (for example, via parenting practices as a result of the variety and quality of parents' networks) (Cochran \& Niego, 2002). For preschoolage children, research has tended to focus more on indirect influences through parenting practices. A review of the literature on parenting practices found that mothers with higher levels of social support behaved in a more positively nurturing way towards their children than those with fewer social connections (Ceballo \& McLoyd, 2002). Greater parental social connectedness has also been shown to lower the incidence of both violence towards and neglect of children in the home (Spilsbury \& Korbin, 2013). Furthermore stronger parental connectedness has been associated with an increase in parental warmth and having a more stimulating home (Marshall, Noonan, McCartney, Marx, \& Keefe, 2001), more effective parenting styles, better parent/child communication and mentoring (Byrnes \& Miller, 2012). 
A significant feature of much of the research, however, is that it has been conducted with families and/or in areas characterised by moderate to severe poverty or in developing country settings (McPherson et al., 2013). However, a recent review suggests more general concerns about social connectedness across Australian cities (Kelly et al., 2012). In relation to families with children, Woolcock, Gleeson and Randoph (2010) highlight two particular areas of concern in Australian cities; children being raised in medium to high density inner urban areas where neighbourhoods are focused towards singles and couples without children, and children being raised in new housing states on the outer urban fringe.

In order to address some of these concerns, the current study aims to explore the social networks of parents of preschool-age children in two different Australian urban locations; namely an inner and an outer municipality of Melbourne to investigate the meaning of social connections and identify any differences in patterns of social connections.

\section{Method}

This was a mixed methods study of parents of pre-school-age children, who lived in selected inner and outer suburban municipalities one located $>25 \mathrm{~km}$ and the other $<10 \mathrm{~km}$ from the central business district of Melbourne, Australia. The suburbs selected were middle income areas with similar socioeconomic profiles and were chosen as they were home to the highest percentage of children aged 0-4 years for an inner and outer municipality of Melbourne (Australian Bureau of Statistics [ABS], 2011). This study was approved by the Deakin University Human Ethics Committee prior to commencement of the research (approval number: HEAG-H 97_2011).

The study took a stratified purposive approach to recruitment of parents. To be eligible, participants were required to be a parent with at least one preschool-age child, who had lived in their municipality for at least 12 months. Participants were recruited via key community services for families with young children. These included maternal and child health services, mothers' groups, playgroups, childcare centres, community centres and preschools. Parents were recruited via fliers displayed in, or distributed to, users of the service. All the participants were women and had 
similar demographic characteristics (see Table 1).

Table 1

Parent Characteristics

\begin{tabular}{|c|c|c|}
\hline Characteristic & Inner-municipality & Outer-municipality \\
\hline Age (years) & $32-42$ & $27-42$ \\
\hline Marital status & $\begin{array}{l}\text { Partnered }(n=8) \\
\text { Single }(n=2)\end{array}$ & Partnered $(n=10)$ \\
\hline $\begin{array}{l}\text { Number of preschool } \\
\text { children }\end{array}$ & $1-2$ & $1-3$ \\
\hline Age range of children & 8 months -4 years & 7 months -5 years \\
\hline Working arrangement & $\begin{array}{l}\text { Home full time }(n=4) \\
\text { Employed part time }(n=6)\end{array}$ & $\begin{array}{l}\text { Home full time }(n=4) \\
\text { Employed part time }(n=6)\end{array}$ \\
\hline Highest qualification & $\begin{array}{l}\text { Apprenticeship }(n=1) \\
\text { Certificate level }(n=2) \\
\text { University level }(n=7)\end{array}$ & $\begin{array}{l}12 \text { years of school }(n=1) \\
\text { Certificate level }(n=4) \\
\text { University level }(n=5)\end{array}$ \\
\hline $\begin{array}{l}\text { Outlay on mortgage } \\
\text { payments (fraction of } \\
\text { household income) }\end{array}$ & $\begin{array}{l}1 / 4 \text { or less }(n=3) \\
1 / 4-1 / 3(n=3) \\
1 / 3 \text { or more }(n=4)\end{array}$ & $\begin{array}{l}1 / 4 \text { or less }(n=2) \\
1 / 4-1 / 3(n=4) \\
1 / 3 \text { or more }(n=4)\end{array}$ \\
\hline $\begin{array}{l}\text { Length of time in } \\
\text { residential location }\end{array}$ & $\begin{array}{l}1-4 \text { years }(n=7) \\
5 \text { years or more }(n=3)\end{array}$ & $\begin{array}{l}1-4 \text { years }(n=7) \\
5 \text { years or more }(n=3)\end{array}$ \\
\hline
\end{tabular}

Data were collected via two interviews. The first, face-to-face interviews collected primarily quantitative information, eliciting details of mothers' social networks and a range of information on their views of their local area, health and sociodemographic characteristics. The second was a semi-structured interview which elicited rich qualitative data on the same topics.

A detailed description of the mothers' social networks was developed using the 
'name generator' approach (Marsden 2006; Valente, 2010). Participants were asked who they had contact with about their children, particularly those who were under five years old. Prompts mentioned that contacts could include those they talked to or had contact with about their children's growth and development, their health, education, childcare or babysitting. This could include their partner, friends and family, people they talked with socially, work colleagues, neighbours, people in education, health or childcare services, or any other links that came to mind. They were then asked about people they had contact with about local or neighbourhood issues, those that they have contact with in relation to social or political issues, work contacts, people who were important to them in relation to their own health and wellbeing, those they turned to or with whom they discussed personal issues such as relationships, those that they would seek help or advice from in the event of a personal or health crisis, and anybody else who was important to them that they hadn't yet mentioned.

For each of the contacts mentioned, participants were asked: How long they had known that person (coded as: less than one year, one to less than five years, five to less than 10 years and ten years or more); Where they lived (coded as: in the same postcode area, elsewhere in the same local government area, elsewhere in Melbourne, and elsewhere); When they were in contact most recently (coded as: in the last 24 hours, more than one day but less than one week ago, one week ago, more than one week but less than one month ago, more than one month up to one year ago, more than one year ago); How frequently they are usually in contact? (coded as: daily, less frequently than daily but more than weekly, less frequently than weekly but more than monthly, less frequently than once a month, but more than once per year, annually, less frequently than once per year); The type of contact (coded as: In person, by phone, electronically [e.g. internet, email, social networking sites] or other) ; Whether they first met that person through any local organisations or services discussed in earlier parts of the questionnaire) (yes or no); Whether they ever see or meet the person at any of those organisations, services or facilities (yes or no); Which of the people they had mentioned know each other.

Questionnaire data were entered into SPSS and descriptive and social 
network analyses conducted. Due to the small sample size no formal statistical testing was conducted. Rather differences of a meaningful magnitude (minimum of $25 \%$ difference between groups) were identified and reported.

The second semi-structured interview of about one hour's duration was conducted either face- to-face or by telephone, and consisted of open-ended questions focusing on mothers' ideals for a good place to raise a family and their experiences of raising their children in their current location. The qualitative interviews were recorded, transcribed verbatim and analysed thematically. Analysis of the qualitative data followed methods described in detail previously (Andrews, Rich, Stockdale, \& Shelley, 2014). Briefly, a deductive approach was taken initially, involving data coding and grouping of codes into themes (Creswell, 2009). After analysing approximately half the interviews, the researcher (FJA) revisited the literature and identified the Environments for Health framework (Victorian Government, 2001) as a useful tool to provide structure to the analysis. The remainder of the interview analysis employed a more inductive approach with transcript coding being informed specifically by the four dimensions in the Environments for Health framework; built/physical, economic, social or natural. In the current study, only material related to the social dimensions of parents' experiences were analysed.

\section{Results}

\section{Importance of social networks}

A finding common to participants from both municipalities was the potential for mothers with young children to become socially isolated and the importance of social support to alleviate this during this period of their lives. At the same time, mothers also spoke of their young children often being a trigger for initiating social connections. One mother from an inner suburb explained:

Before we had children, I didn't actually know anyone... but I guess when you have kids and you're home more often, you need local friends. So you need a network, so I guess I probably sought people out more. And being involved in 
playgroups and mother's group you meet people. So yes now that l've got kids I feel quite a part of the community, and I would like to be more involved and know more people. Yeah I do like kind of walking down the street and recognising faces, having people my kids know, I think that's really nice. But yeah before we had children I wouldn't have even known the local person in coffee shop. (P12)

\section{Size of networks}

The number of contacts named by mothers in each of the two areas was very similar, with an average of eight contacts mentioned in both areas. However, there was an indication that more of the outer suburban mothers had very few contacts, with more than a third of this group naming six or fewer contacts, compared with just under $10 \%$ of inner city mothers. Similarly, fewer of the outer area mothers named 10 or more contacts: $12 \%$ compared with $36 \%$ of inner area mothers. This was supported by findings from the semi-structured interviews where some clear differences between women's social connections in the inner and outer suburbs emerged. Mothers from the inner suburbs tended to have stronger, supportive social connections from a range of sources in their local community. For example one woman said:

I think you know, l've felt pretty well supported in that l've got a bunch of women around me who I can call on for help, who are all doing the same sort of stuff, they're having better days and worse days. (P4)

In contrast, mothers from the outer suburbs spoke of having fewer stronger social connections in their local neighbourhood with some women describing having few social supports other than their partners:

So in terms of raising Ali it's just me during the day and then my husband when he comes home from work... So during the weekday Monday to Friday, nine to six, l've got no one... which is tiring and it is hard. (P1)

Despite the fact women had lived in their residential locations for a similar period 
of time, there were indications, also, that mothers in the outer suburban area had more network members that they had known for less than one year. A quarter of the mothers in the outer area had known more than one third of their network members for less than one year, whereas fewer than $10 \%$ of the inner suburb mothers had a high proportion of relatively new members in their networks.

\section{Neighbours as contacts}

One reason for the difference in social connections amongst women from the two areas appeared to relate to their relationships with their immediate neighbours. Whereas almost three-quarters (73\%) of the mothers in the inner suburbs area named one or more neighbours amongst their important contacts, only one-quarter $(25 \%)$ of those in the outer suburbs did so. This was mirrored in the open-ended interviews where women from the inner suburbs tended to describe much stronger relationships with their neighbours. One woman explained:

I can go and ask any of my neighbours and say look l'm going away in two days, just unexpected, (and I'm talking all of them not just one person), 'Oh you don't mind getting the mail for me, or can you feed my tomatoes, you know what I mean or take my bins out? (P20)

For many this extended to their neighbours helping them in raising their children. For example one woman said:

In terms of having a young family it's amazing. You know people who will share drop offs at school or kinder, just that sense of, if you needed a backup you've got it. And I mean I have a lot of family back up but, I also know I could probably ring six or seven people who I feel if I needed other back up. (P11)

Women from the outer suburbs however, described more superficial relationships with their neighbours. One woman when talking about her neighbours said:

It's a sort of hi how are you small conversation. It's yeah, it's friendly but, it's not 
like we have any extended contact. So we're quite happy to have a chat about the weather or how's my daughter, like they all know about her but, you know we don't go over there for coffee or dinner or anything. But like we are able to say hello when we walk past. (P14)

Even where women did report knowing a neighbour, for most this did not extend to support in raising their children:

I don't know them well enough to say here have my kids for the afternoon. I can say l've got to quickly run down the street can you just sit with the kids, I can do that, but I can't you know leave them for a certain amount of time. I don't feel that I know them well enough yet to do that. (P5)

Qualitative interviews revealed several reasons why women in the inner suburbs might have had stronger relationships with their neighbours. Firstly, they reported relationships with neighbours as a higher priority for a good place to raise a family than women from the outer suburbs. One woman from the inner suburbs explained that a strong ideal for a good place to raise a family was:

A community where you feel welcome. Somewhere you go down the street and you know, you can informally bump into people and have chats, rather than just planned meetings. Having people around that if something happens you can just drop the kids off at their place, or the kids can come over and play... People looking outwards rather than looking inwards... people looking out for you, so you're not on your own. (P6)

In contrast women from the outer suburbs said:

Neighbours... not in each other's pockets. (P7)

Good neighbours... It's not a high, high, priority but it's nice. (P3)

Another explanation for the difference in relationships with neighbours appeared to be linked to the physical design of the different neighbourhoods. In the inner 
suburbs, women reported regular incidental contact with their neighbours and opportunities to get to know each other 'out the front' of their homes.

I just see them [my neighbours] out in the street... my kids are out the front and then they see other kids and they're like 'who's that Mummy?' so that's when I walk up and say hi I'm Julie, this is my daughter, and the kids will have a little play. (P10)

In our block you see people coming home and everything is relatively close, so there's a lot of g'day how you doing and lots of informal chats. (P6)

In contrast, in the outer suburbs more women reported driving around their neighbourhoods and entering their houses via their garages so there was less opportunity for incidental contact.

I've met the next door neighbours, we only know them to say hello. I suppose we go into the garage and we're never really out in the front so we rarely ever see them, only when you we're driving up and down the street. (P18)

I think people are just all in their own little lives and comings and goings and we're actually not really engaging... cos there's not the opportunity... Unless you're out the front doing you're gardening... like most people I never go out of my front door... like I always go via the garage door. (P21)

One woman from the outer suburbs who did know a neighbour well, went on to explain that she had got to know her, because, unlike most houses in the area, her neighbour's house had an enclosed front garden.

Because they've got two little boys who play in their front yard but they're able to because it's all fenced so they can't get out on the road... And like now if I run out of milk I'll just run over there... You know it actually quite clichéd but we've actually borrowed sugar and stuff off each other. (P7)

\section{Location of contacts}


Mothers in both areas had met at least some of their network members through local organisations or services. On average, however, outer suburban mothers had met a greater proportion of their contacts in this way ( $47 \%$ compared with $28 \%$ of contacts for inner suburban mothers), with $12 \%$ of this group having met more than half of their contacts this way, whereas none of the inner suburban mothers were reliant on local facilities as a source of all of their contacts. This was supported by the qualitative findings where mothers from the outer suburbs reported being heavily reliant on organisations and services for social contacts. One mother explained:

It's not easy to break into anything unless you're thrown in with a whole group of new people like we were with the kinder. (P19)

Although mothers from both the inner and outer suburbs both described organised activities such as playgroups and mother's groups as good places to develop social connections, mothers from the inner suburbs appeared to have met more of their network members through incidental contact, particularly in local parks. For example one mother explained:

And a lot of time we meet people through other people, like you know just down at the park and stuff like that, you know hanging out with you, you might know someone and they might know someone and then they know someone... and then you know the cafes, you get to know a lot of people that way. Yeah you see the same faces around I guess...You might get talking to people down at the park just out of the blue because the kids are playing or they're patting the dog... there's a lot of opportunities for people to get to know each other. (P16)

Given the reliance women from the outer municipality placed on organised activities for making social connections in their community it was unsurprising that they, more than the inner suburban, women spoke of the need for more formal opportunities to meet other mothers.

Within our community like once a year, we the sort of body corporate, I mean we pay for it as home owners but, they like organise a Christmas party and that's 
every year. So I suppose there is an opportunity once a year to meet people that live within the neighbourhood, in your estate. But you know that's only once a year. $(P 1)$

There's opportunities here but I think people are crying out for more. (P3)

\section{Diversity of contacts}

The final difference in relation to women's different social connections in the two municipalities related to the diversity of connections. Women in the inner suburbs, whilst valuing connections with other mothers of preschool-age children, also spoke about the diversity of their communities, particularly in terms of age structure and how this was helpful in supporting them to raise their children. One woman said:

Most people have been here a while, like they have been here for twenty years, so their kids have grown up in the area. Yeah so even though there are different ages and different family situations that don't stop the community becoming close. Because you can learn a lot from someone that has been here thirty years to someone who's just been here for two years. (P20)

Another when talking about her elderly neighbour relationship with her son said:

I like that sense of connectedness because I think it teaches kids a sense of responsibility as well, you can't get away with stuff you know. You're not anonymous in the world. So you can't just do whatever you feel like doing without that accountability. (P13)

In contrast, no women from outer suburbs described living in age-diverse neighbourhoods and none spoke of receiving support from older neighbours or members of their community in raising their children. One woman explained:

It's good to have diversity with ages but to be honest there's not many retired couples in my area. Like in my street, out of say fifteen houses, there might be two. And there's the aged care facility, they have an aged care home in my 
neighbourhood but then that's separate. (P7)

There were strong contrasts, also, in the make-up of the social networks of mothers in the two areas related to the role of service providers. Three-quarters $(75 \%)$ of mothers in the outer area named their general practitioner as one of their important contacts, compared with about one-third (36\%) of those in the inner area. If service providers were not counted among contacts, several outer area mothers had very small social networks.

\section{Discussion}

While confirming previous research demonstrating the importance of social connections for parents raising preschool age children (Darlington, 2002; Devolin et al., 2012; Hogg \& Worth, 2009; Miller \& Hanna et al., 2002), this small study has demonstrated some key differences in the social connections of mothers of preschool-age children between an inner and outer suburban area of Melbourne. These findings fill a gap in the literature as despite social connections being important to parents of young children, there have been few studies comparing social connectedness amongst parents across Australian cities.

Overall, inner suburban mothers reported greater local connectedness, characterised by strong and supportive links with neighbours and others in the local area, incidental contact with neighbours and others in the area that supported making and maintaining links and enabled frequent, in-person contact with network members. In contrast, outer suburban mothers were less likely to include neighbours in their social networks or to value connections with those who lived close by. Their networks showed less diversity than those of the inner-suburban mothers, with a higher proportion of women appearing quite socially isolated and women more dependent on organised services as a means of meeting and seeing others in their networks. These findings differ from an older study comparing neighbourliness across Melbourne, where Brownlee (1993) found families from outer suburbs felt more supported by their neighbours with child-related activities than those from inner suburbs. However, not only have the demographics of Melbourne changed considerably since this study was 
conducted with many more families choosing to raise children in inner suburban areas (ABS, 2011), unlike our study, not all respondents to Brownlee's survey were parents, and there were significant differences in socioeconomic status between the suburbs studies.

There were however, other differences in the physical and social environments of inner and outer suburbs that appeared to contribute substantially to the patterns of social connections displayed by the mothers in our study. The denser and more walkable layouts of inner suburban areas increased the opportunities for mothers to meet and have incidental contact with neighbours and others in their local area. In the outer suburbs, reliance on cars, houses that enable residents to enter the house from the garage and unfenced front yards (the latter often mandated by developers), all contributed to the lack of this incidental contact with neighbours, supporting the findings of previous studies (Andrews et al., 2014; Tranter, 2006; Williams, Pocock, \& Bridge, 2009).

Of course, there are numerous factors contributing to the patterns observed in this study. As has been shown elsewhere (Andrews, 2010; Green, 2009; Kim et al., 2005), people select the areas in which they live and where they choose to raise their families for a range of reasons. Hence the lack of incidental contact with neighbours in the outer suburbs is, in part, a choice made by those that live in these areas, as is a lifestyle dominated by car use, considerable space around and between houses that allows children to play in more safety in backyards rather than in front yards or on footpaths (Andrews, 2010; Williams et al., 2009). The interaction of composition and context does however, raise the need for developers and local councils to consider the social interactions that the spaces and developments they plan engender, in the same way that they are increasingly considering the impact of the built environment on physical activity (McCormack \& Shiell, 2011), particularly given the growing body of literature demonstrating the association between social connections and health outcomes for both parents (Morgan \& Eastwood, 2014) and children (McPherson et al., 2013).

Finally, our findings suggest also that there is a higher need for a range of organised activities in outer suburban areas to assist residents in those areas to form 
larger social networks. Even though it is clear from the existing literature that all parents of pre-school-age children need informal activities (Devolin et al., 2012; Hanna et al., 2002; Hogg, 2009; Miller \& Darlington, 2002), the composition of the population who seek to live in the inner suburbs while raising a young family together with the form of the built environment, are conducive to inner suburban residents forming their own formal and informal networks of support. In contrast, mothers who live in outer suburbs seemed to both choose and require a more organised approach to the development of their social networks. The interesting observation in the current study that outer suburban women included their general practitioner as one of the social network contacts, may be a reflection of their limited informal support from older, more experienced parents in their suburbs. This is supported by the work of Williams et al. (2009) who observed that 'historical sediment' characterised by stable long-lived communities and older people offering deeper forms of social support is more prevalent in more established suburbs of Australian cities than newer, masterplanned communities. Clearly, there are important roles for local councils, developers and community services in ensuring that the appropriate levels of support are provided for women in the growing outer suburbs of Australian cities.

The results presented here are based on a small sample size of mothers, studied at only one point in time. As a result, the sample may not include the full range of diversity present within the two municipalities. In particular, it is likely to underrepresent those with the least connections within the local area, those who do not access formal services or who move within social groups that this study did not access. However, the use of a mixed methods design for this study has enabled us to provide quantitative information with greater depth and understanding of the meaning of the results provided by the qualitative information from the in-depth interviews.

\section{Conclusion}

There were clear differences in the make-up, diversity and importance of social connections between parents living in inner and outer suburbs. This may reflect different priorities parents placed on neighbours, barriers experienced in connecting with neighbours in the outer-suburbs and the consequent heavy reliance on 
organised activities to form social connections. The different types of social connections parents in inner and outer-Melbourne made in relation to raising their preschool-aged children revealed in this study has implications for service delivery and social planning of new developments across Australian cities as well as for a range of early childhood professionals. Clearly, further research is needed to disentangle cause and effect in relationships between the built and planned form of suburbs and the nature of social interactions.

\section{Acknowledgements}

This study was funded by a grant from the School of Health \& Social Development, Deakin University. The authors are grateful to the parents who participated in this study and Council staff who assisted with recruitment.

\section{References}

Andrews, F. J. (2010). Parental perceptions of residential location: Impacts on children's health. Health and Place, 16, 252-258.

Andrews, F. J., Rich, S., Stockdale, R., \& Shelley, J. (2014). Parents' experiences of raising pre-school aged children in an outer-Melbourne growth corridor. Health and Place, 27, 220-228.

Australian Bureau of Statistics. (2011). Census. Australian Bureau of Statistics, Canberra.

Baker, D. (2012). All the lonely people. Loneliness in Australia. Institute Paper No. 9, Australia Institute.

Berkman, L. F. (1995). The role of social relations in health promotion. Psychosomatic Medicine, 57(3), 245-254.

Bost, K. K., Cox, M. J., Burchinal, .M R., \& Payne, C. (2002). Structural and supportive changes in couples' family and friendship networks across the transition to parenthood. Journal of Marriage and Family, 64(2), 517- 531.

Brownlee, H. (1993). Who needs neighbours? Views from the outer and inner suburbs? Family Matters, 35, 34-36.

Byrnes, H. F., \& Miller B. A. (2012). The relationship between neighborhood characteristics and effective parenting behaviors: The role of social support. Journal of Family Issues, 33, 1658-1687.

Cattell V. (2011). Poverty, community and health. [Online]. Retrieved from http://www.palgraveconnect.com/pc/doifinder/10.1057/9780230355101

Caughy M. O., O'Campo P. J., \& Muntaner C. (2003). When being alone might be better: neighborhood poverty, social capital, and child mental health. Social Science and Medicine, 57(2), 227-237. 
Ceballo, R., \& McLoyd, V. C. (2002). Social support and parenting in poor, dangerous neighbourhoods. Child Development, 73(4), 1310-1321.

Cochran, M., \& Niego, S. (2002). Parenting and social networks. In Handbook of Parenting. 2 edition Volume 4. Marwah, New Jersey; Lawrence Erlbaum Associates.

Creswell, J. (2009). Research design: Qualitative, quantitative and mixed methods approaches. London: Sage Publications.

Devolin, M., Phelps, D., Duhaney, T., Benzies, K., Hildebrandt, C., Rikhy, S., \& Churchill, K. (2012). Information and support needs among parents of young children in a region of Canada: A cross-sectional survey. Public Health Nursing, 30(3), 193-201.

Edwards, B. (2006). Views of the village: parents' perceptions of their neighbourhoods. Family Matters, 74, 26-33.

Edwards, B., \& Bromfield, L. M. (2009). Neighbourhood influences on young children's conduct problems and pro-social behaviour: Evidence from an Australian national sample. Children and Youth Services Review, 31, 317-324.

Edwards, B., \& Bromfield, L. M. (2010). Neighbourhood influences on young children's emotional and behavioural problems. Family Matters, 84, 7-19.

Green, A. E. (2009). A question of compromise? Case study evidence on the location and mobility strategies of dual career households. Regional Studies, 31, 641-657.

Hanna, B. A., Edgecombe, G., Jackson, C. A., \& Newman, S. (2002). The importance of first-time parent groups for new parents. Nursing and Health Science, 4, 209214.

Hogg, R., \& Worth, A. (2009). What support do parents of young children need? A user-focused study. Community Practitioner, 80(1), 31-34.

Holt-Lunstad, J., Smith, T. B., \& Layton J. B. (2010). Social relationships and mortality risk: A meta-analytic review. PLoS Med, 7, e316.

Kelly, J. F., Breadon, P., Davis, C., Mares, P., Mullerworth, D., \& Weidmann, B. (2012). Social cities. Melbourne: Grattan Institute.

Kim, T. K., Horner, M. W., \& Marans, R. W. (2005). Life cycle and environmental factors in selecting residential and job locations. Housing Studies, 20, 457-473.

Marsden, P. V. (2006). Network methods in social epidemiology. In J. M. Oakes, \& J. S. Kaufman (Eds.), Methods in social epidemiology (pp. 267-286). San Francisco, USA: Jossey-Bass.

Marshall, N. L., Noonan, A. E., McCartney, K., Marx, F., \& Keefe, N. (2001). It takes an urban village: Parenting networks of urban families, Journal of Family Issues 22, 163-182.

McCormack, G. R., Shiell, A. (2011). In search of causality: A systematic review of the relationship between the built environment and physical activity among adults. International Journal of Behavioral Nutrition and Physical Activity, 8 (125), doi:10.1186/1479-5868-8-125

McPherson, K. E., Kerr, S., Morgan, A., McGee, E., Cheater, F. M., McLean, J., \& Egan, J. (2013). The association between family and community social capital and health risk behaviours in young people: An integrative review. BMC Public Health, 13 (1), 971, doi:10.1186/1471-2458-13-971 
Miller R. J., \& Darlington, Y. (2002). Who supports? The providers of social support to dual-parent families caring for young children. Journal of Community Psychology, 30(5), 461-473.

Morgan, K. J., \& Eastwood, J. G. (2014). Social determinants of maternal self-rated health in South Western Sydney, Australia, BMC Research Notes, 7, 51, doi:10.1186/1756-0500-7-51

Small, R., Taft, A., \& Brown, S. (2011). The power of social connection and support in improving health: lessons from social support interventions with childbearing women, BMC Public Health, 11 (Suppl 5), S4, doi:10.1186/1471-2458-11-S5-S4

Spilsbury, J. C., \& Korbin, J. E. (2013). Social networks and informal social support in protecting children from abuse and neglect. Child Abuse \& Neglect, 37S, 8-16.

Tranter, P. (2006). Overcoming social traps. In B. Gleeson \& N. Sipe, (Eds.), Creating child friendly cities: Reinstating kids in the city (pp. 121-135). Oxford, UK, Routledge.

Valente, T. W. (2010). Social networks and health: Models, methods, and applications. New York: Oxford University Press.

Victorian Government. (2001). Environments for health. Promoting health and wellbeing through built, social, economic and natural environments. Municipal Public Health Planning Framework, September 2001.

Williams, P., Pocock, B., Bridge, K. (2009). Linked up lives: Putting together work, home and community in ten Australian suburbs. Overview Report. University of South Australia, Centre for Work \& Life.

Woolcock, G., Gleeson, G. \& Randolph, B. (2010). Urban research and child-friendly cities: a new Australian outline. Children's Geographies, 8, 177-192.

Xue, Y., Leventhal, T., Brooks-Gunn, J., \& Felton, J. (2005). Neighbourhood residence and mental health problems of 5-11 year olds. Archives of General Psychiatry, 62, 554-563.

\section{Biographical notes}

Dr Fiona Andrews, MHlthSc, PhD is a Lecturer at Deakin University, School of Health and Social Development. She has research interests in the relationship between neighbourhoods, health and families, with a particular focus on parents of preschoolaged children and has research partnerships with several local governments in Melbourne. Dr Andrews lectures in family health and wellbeing, health, place and planning.

Associate Professor Julia Shelley, MPH, PhD holds the positions of Associate Professor in the School of Health and Social Development and Deputy Director, Centre for Health through Action on Social Exclusion (CHASE), Faculty of Health, Associate Professor Shelley is a social epidemiologist with research and teaching 
interests in reproductive and sexual health, social connectedness and social and health inequalities.

Ms Stephanie Rich BHIth Sci (Hons) is a Health Promotion Officer specialising in women's health and wellbeing. She has previously worked in research in the areas of reproductive and sexual health, gender, family violence and Indigenous health.

Ms Alexandra James, BA (Hons), BCom, is a PhD candidate in the School of Social and Political Sciences at Monash University. She recently completed a first class Honours Degree in Sociology at Deakin University. Currently employed by Deakin University as a tutor in the School of Humanities and Social Sciences, she has previously worked within the School of Health and Social Development. She has specific research interests in women's and gender studies. 